\title{
THE EFFECT OF EIGHT THERMAL PROTECTANTS ON THE SURVIVAL RATE AND THE VIABLE COUNTS OF LACTOBACILLUS CASEI AFTER HEAT TREATMENT IN FERMENTED GOAT MILK
}

\author{
- Research paper - \\ Qiqi ZHENG ${ }^{*}$, Guowei SHU*, Jianbo KOU*, Xiuxiu CUI**, Jiangpeng MENG ${ }^{\text {*** }}$ \\ *School of Food and Biological Engineering, Shaanxi University of Science \& Technology, \\ Xi'an, 710021, China \\ ${ }^{* *}$ Department of Research and Development, Xi' an Baiyue Gaot Milk Corp., Ltd., Xi'an \\ 710089, China
}

\begin{abstract}
In order to improve the survival rate of probiotics and produce probiotic goat milk from fermented goat milk of Lactobacillus casei L61 by spray drying. Spray drying has been applied to large-scale industrial production of milk powder due to its high efficiency and low cost. However, high temperatures in spray drying can result in the loss of large numbers of probiotic.The purpose of this paper is to study the effects of eight thermal protectants including skim milk, sucrose, glucose, $\beta$-cyclodextrin, gelatin, maltodextrin, glycerol, trehalose on the survival rate and viable counts of L.casei L61 after heat treatment by the single factor experiment. All protective agents have a positive effect on increasing the survival rate of L.casei L61 $(p<0.05)$. The results indicated that the survival rates of L.casei L61 were up to the maximum of $10.94 \%, 1.13 \%, 3.04 \%$, $0.21 \%, 6.97 \%, 0.075,4.71 \%$ and $0.29 \%$, while the additions of skim milk, sucrose, glucose, $\beta$-cyclodextrin, gelatin, maltodextrin, glycerol, trehalose were $20 \mathrm{mg} / \mathrm{L}, 10 \%, 7 \%, 15 \%, 1.5 \%, 3 \%, 8 \mathrm{~mL} / \mathrm{L}, 10 \%$, respectively; the viable counts after heat treatment are $19.69,0.81,1.78,0.455,12.2,0.12,2.75,0.435\left(\times 10^{6} \mathrm{CFU} / \mathrm{mL}\right)$, respectively. This paper provides technical a reference for the development of probiotic goat milk powder.
\end{abstract}

Keywords: Lactobacillus casei; thermal protectants; spray drying; goat milk; heat resistance.

\section{INTRODUCTION}

Goat milk and its products are favored by consumers because of its composition close to human milk and have high levels of free amino acids (Haenlein, 2004). Probiotic microorganisms play an important role in the fermented food industry as starter culture (Chen et al., 2017). Commercial starter cultures have been widely used in fermented foods. The starter culture can contribute to the attributes of foods, such as texture, amora, and also inhibit some pathogenic microorganisms (Johansen, 2018). The lactase enzymes from the starter culture in the dairy product ensure that the lactose in the human gut reaches a level that does not cause adverse reactions (Posecion et al., 2005).

The large-scale lactic acid bacteria drying products have attracted more and more attention in recent years with increasing market demand (Su et al., 2018). Spray drying and freezing drying are most common processes to obtain dry productions (Yonekura et al., 2014). Freeze-drying is a time-consuming and high cost process (Her et al., 2015; Agudelo et al., 2017). By contrast, spray drying is a faster, higher productivity technique that effectively transforms microorganisms into solids to increase shelf life in powder production (Gharsallaoui et al., 2007). However, probiotic microorganisms are usually sensitive to heat. High temperatures in spray drying can cause microbial cell damage (Nunes et al., 2017). Thus, in order to prevent these damages, the thermal protectants were required to protect starter culture. Several types of protection for probiotics have been studied, trehalose has the best thermal protective potential (Nunes et al., 2017).

Mandal et al (2006) embedded Lactobacillus casei NCDC-29 in different concentrations of

\footnotetext{
${ }^{1}$ Corresponding author. E-Mail addres: byjpmeng@gmail.com
} 
sodium alginate, and treated for a period of time under low $\mathrm{pH}$, high bile salt concentration and heat treatment conditions. The test results showed that the Sodium alginate has a certain bacterial protection effect. The effect of different trehalose concentrations on the viable counts of spray-dried rhamnose lactobacillus GG and Lactobacillus rhamnosus E-97800 powder were studied (Sunny-Roberts et al., 2009; Ying et al., 2012). Ananta et al (2005) concluded that skim milk, oligofructose or polydextrose have a good protective effect on Lactobacillus rhamnosus GG. Chávez et al (2007) demonstrated that the sugars have protective effects by using soy protein and maltodextrin or skim milk and gum arabic as heat-resistant protective agents.

The Lactobacillus casei, a kind of gram-positive bacteria, can help to improve aberrant bowel movements and is effective against respiratory infections (Isolauri et al., 1991). Lactobacillus casei has been widely

\section{MATERIAL AND METHODS}

Microorganism: L.casei L61, obtained from school of Food and Biological Engineering, shaanxi University of Science and Technology, was inoculated into the sterile MRS broth medium (MRS, Hopebio, Qingdao, China), mixed well, and then cultured in a $37^{\circ} \mathrm{C}$ incubator for 24 hours to obtain a generation of activation solution, and then the above activation solution was taken as $5 \%(\mathrm{v} / \mathrm{v})$ was inoculated in MRS broth medium and cultured at $37^{\circ} \mathrm{C}$ for $24 \mathrm{~h}$ to obtain a second-generation activating solution, and the activation was repeated for three generations, and the third-generation culture time was $18 \mathrm{~h}$. The third-generation bacterial solution obtained above was inoculated into the reconstituted goat milk medium at a $5 \%(\mathrm{v} / \mathrm{v})$ inoculum, and the mixture was thoroughly mixed, and then fermented to a complete curd in a $37^{\circ} \mathrm{C}$ constant temperature incubator, taken out and stored in the refrigerator at $4{ }^{\circ} \mathrm{C}$.

Preparation of Fermented Goat Milk: The defatted goat milk powder was formulated into a reconstituted milk with a concentration of used in fermented foods because of its good cholesterol-lowering and anti-tumor effects (Her et al., 2015).

In the previous work, four strains with good antioxidant capacity and DPPH clearance rate have been screened, among which the most heat resistant is L.casei L61 (Chen et al., 2012). The optimal nutritional formula for antioxidant peptide production by Lactobacillus casei have been explored (Shu et al., 2018). In this study, the effects of eight thermal protectants (skim milk, sucrose, glucose, $\beta$-cyclodextrin, gelatin, maltodextrin, glycerol, trehalose) on the heat resistance of Lactobacillus casei L61 in fermented goat milk were investigated by single factor experiments. Subsequently, the optimal protection conditions of each thermal protectants were obtained and the protective mechanism of protective agents was preliminarily explored to provide technical support for the production of antioxidant peptide probiotic goat milk powder.

$11 \%$ and pasteurized at $105^{\circ} \mathrm{C}$ for $15 \mathrm{~min}$. After cooling, the activated strain of L.casei L61 was added according to the inoculation amount of $5 \%$, and the fermentation was carried out in a constant temperature water bath at $41^{\circ} \mathrm{C}$. After fermenting for 16 hours, the fermented goat milk was taken out.

Determination of cell counts: Before the heat treatment, the sample of fermented goat milk by L.casei L61 was diluted with MRS medium to determine the number of viable cells. The plates were carried out at $37^{\circ} \mathrm{C}$ for $48 \mathrm{~h}$. The viable counts of L.casei $\mathrm{L} 61(\mathrm{CFU} / \mathrm{mL})$ were obtained in triplicates by plating on the plate and the results obtained were considered as "before heat treatment" data. After a $75{ }^{\circ} \mathrm{C}$ constant temperature water bath for 10 minutes, select the appropriate gradient plate coating to calculate the viable counts (Shu et al., 2015). These results mean after "heat treatment" data. The survival rate was calculated according to following equation:

Survival rates $\%=(\mathrm{CFU} / \mathrm{mL}$ after heat treatment / CFU $/ \mathrm{mL}$ before heat treatment) $\times 100 \%$. 


\section{RESULTS AND DISCUSSION}

Effect of skim milk on viable counts and survival rate of $L$.case $i$ L61

The skim milk powder is formulated into different concentration $(0,10,15,20,25,30$ $\mathrm{g} / \mathrm{L}(\mathrm{w} / \mathrm{v}))$ and sterilized in a water bath at $95^{\circ}$ $\mathrm{C}$ for $15 \mathrm{~min}$. After cooling to room temperature. Add to the fermented milk and mix. After heat treatment in a constant temperature water bath at $75^{\circ} \mathrm{C}$ for $10 \mathrm{~min}$, immediately take out and cool, dilute by gradient, and select two suitable gradients for plate coating, three parallels for each gradient, colony count and calculate cell viability. The result was shown in Figure 1. Adding a certain amount of skim milk to the fermented goat milk can enhance the heat resistance of the bacteria and increase the number of viable counts and the survival rate of the cells in the fermented milk per unit volume. In addition, with the increase of skim milk addition, the viable count and survival rate of the bacteria increased rapidly. When the amount of skim milk added was $20 \mathrm{~g} / \mathrm{L}$, the viable count and survival rate reached the maximum, respectively, $19.69 \times 10^{6} \mathrm{CFU} / \mathrm{mL}$. Compared with the control group, the viable count and survival rate were significantly improved

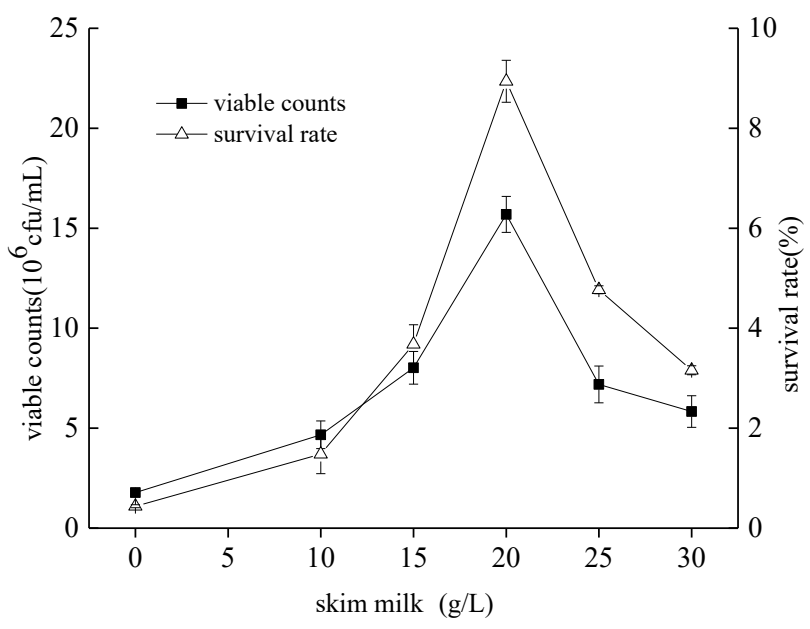

Figure 1. Effect of skim milk on the viable counts and survival rate of L.casei L61

Effect of glucose on viable counts and survival rate of $L$.case $i$ L61

A sterilized glucose solution $(0,1,3,5,7,9 \%$ (w/v)) was added to the $L$. casei L61 fermented milk, and the survival rate was determined by the number of viable cells after heat treatment, the result was shown in Figure 3. When a certain amount of glucose is added, the number $(p<0.01)$. When the amount of skim milk added exceeded $20 \%$, the viable count and survival rate of the cells decreased sharply. It can be seen that skim milk can have a good heat protection effect.

\section{Effect of sucrose on viable counts and} survival rate of $L$.casei $\mathrm{L} 61$

A sterilized sucrose solution was added to the Lactobacillus casei L61 fermented milk to add $0,2,4,6,8,10 \%(\mathrm{w} / \mathrm{v})$, respectively, and the number of viable cells was determined after heat treatment to obtain cell survival rate, the result was shown in Figure 2.

Adding a certain amount of sucrose to the fermented goat's milk is conducive to the survival of the cells under high temperature conditions; as shown in the figure, after the high-temperature water bath is added to the fermented goat milk with sucrose, the viable cell count and cell viability are obvious. Higher than the control group without added sucrose. The results showed that the viable count and survival rate increased with the increase of sucrose addition in the range of sucrose addition $(p<0.05)$. When the sucrose addition amount was $10 \%$, the viable count and the cell viability reached the maximum, which were $0.81 \times 106 \mathrm{CFU} / \mathrm{mL}, 1.13 \%$, respectively.

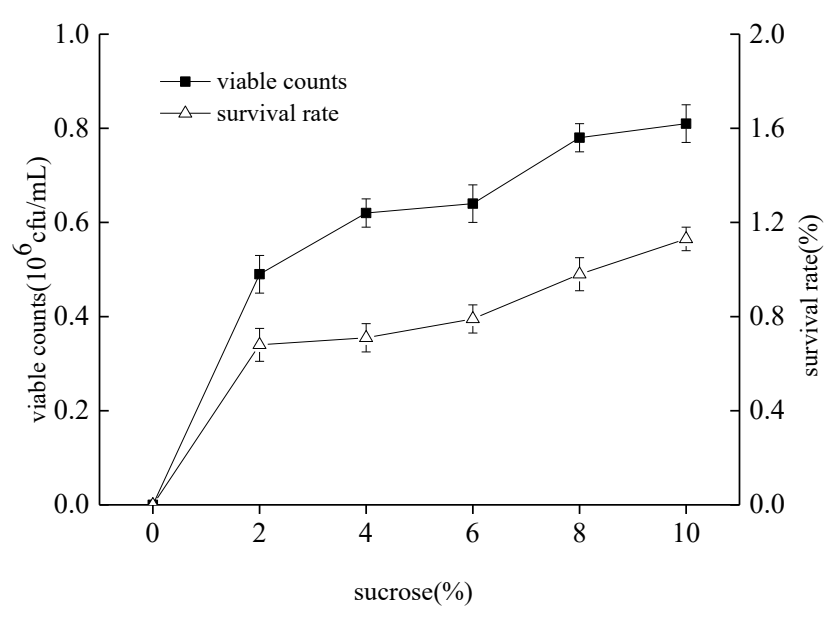

Figure 2. Effect of sucrose on the viable counts and survival rate of L.casei L61

of viable counts and the survival rate after the high temperature water bath can be effectively improved compared with the fermented milk without added glucose $(p<0.05)$. When the amount of glucose added was $7 \%$, the viable cell count and cell viability reached the maximum, meaning $1.78 \times 10^{6} \mathrm{CFU} / \mathrm{mL}$ and $3.04 \%$, respectively. 
Effect of $\beta$-cyclodextrin on viable counts and survival rate of L.casei $\mathrm{L61}$

Sterilized beta-cyclodextrin solution was added to fermented milk of Lactobacillus casei L61, and the dosage was $0,5,10,15,20$ and $25 \%$ $(\mathrm{w} / \mathrm{v})$, respectively. The viability of Lactobacillus casei L61 was calculated by counting the number of viable bacteria after heat treatment. And the results were various as shown in Figure 4. With the increase of dosage, the number of viable bacteria per unit volume

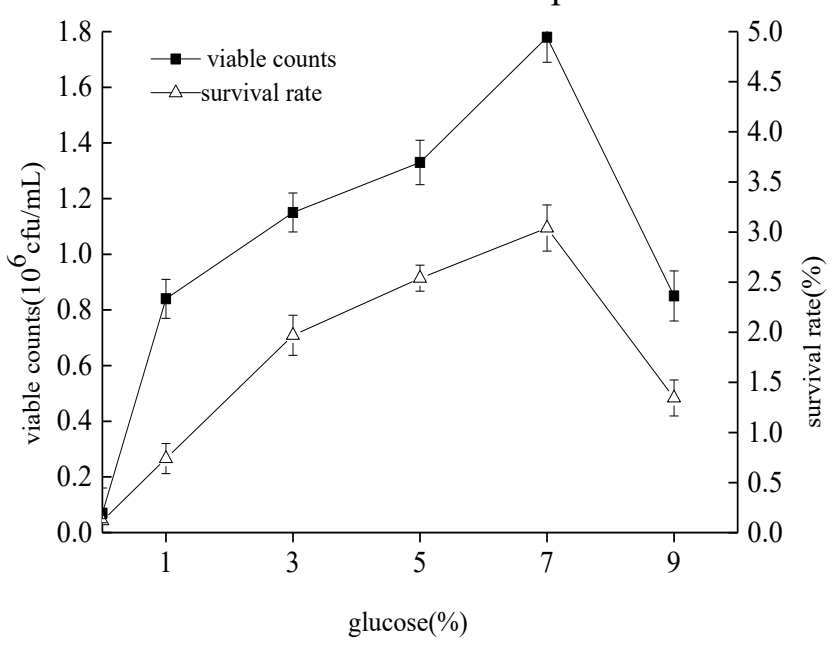

Figure 3. Effect of glucose on the viable counts and survival rate of L.casei L61

Effect of gelatin on viable counts and survival rate of L.case $\mathrm{L} 61$

The gelatin solution after sterilization and cooling was added to goat milk by fermented Lactobacillus casei L61. The additions of gelatin solution were $0,0.5,1.0,1.5,2.0$ and $2.5 \%(\mathrm{w} / \mathrm{v})$, respectively. The viable bacteria were counted after heat treatment to obtain the survival rate of the goat milk. The results were different as shown in Figure 5.

Figure 5 shows that when gelatin has a good heat-resistant protective effect on Lactobacillus casei in fermented goat milk, and different dosages of the same protective agent show different protective effects. From the broken line trend in the Figure 5, with the increase of gelatin content, the number of viable bacteria per unit volume and the viability of bacteria in fermented milk increased first and then decreased $(p<0.05)$. When gelatin content was $1.5 \%$, the number of viable bacteria and viability of bacteria was the highest, which were $12.2 \times 10^{6} \mathrm{CFU} / \mathrm{mL}$ and $6.97 \%$, respectively. and the survival rate of bacteria in the control group increased. When the dosage was $15 \%$, the number of viable bacteria and the survival rate reached the maximum, which were $0.455 \times 10^{6} \mathrm{CFU} / \mathrm{mL}$ and $0.21 \%$, respectively. The results showed that $\beta$-cyclodextrin had a certain effect on enhancing the heat resistance of Lactobacillus casei L61, but the heat protective effect was not particularly significant $(p<0.05)$.

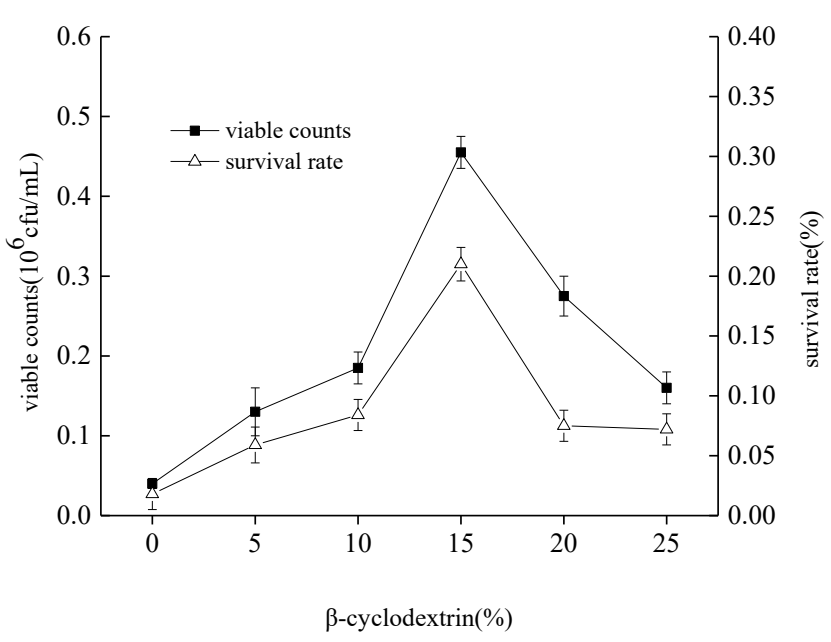

Figure 4. Effect of $\beta$-cyclodextrin on viable counts and survival rate of L.casei L61

\section{Effect of maltodextrin on viable counts and survival rate of L.casei $\mathrm{L} 61$}

The addition of sterilized and cooled maltodextrin solution to goat milk fermented by $L$. casei $\mathrm{L} 61$ was $0,1,3,5,7$ and $9 \%(\mathrm{w} / \mathrm{v})$. The viability of the bacteria was calculated by counting the number of viable bacteria after heat treatment. The results were shown in Figure 6. At first, the number of viable counts and survival rate showed a significant difference with different dosage of the same protective agent. When no protective agent was added, $L$. casei L61 was basically inactivated. With the increase of maltodextrin dosage, the number of viable counts and survival rate of fermented milk per unit volume increased sharply. When the dosage was $3 \%$, the number of live bacteria and survival rate reached the maximum, which were $0.12 \times 10^{6} \mathrm{CFU} / \mathrm{mL}$ and $0.075 \%$, respectively. When the addition of maltodextrin was more than $3 \%$, it showed a slow downward trend. However, it can be seen that maltodextrin has poor thermal protective effect on Lactobacillus casei, and the solubility of maltodextrin is poor, so the follow-up is not a further research object $(p<0.05)$. 


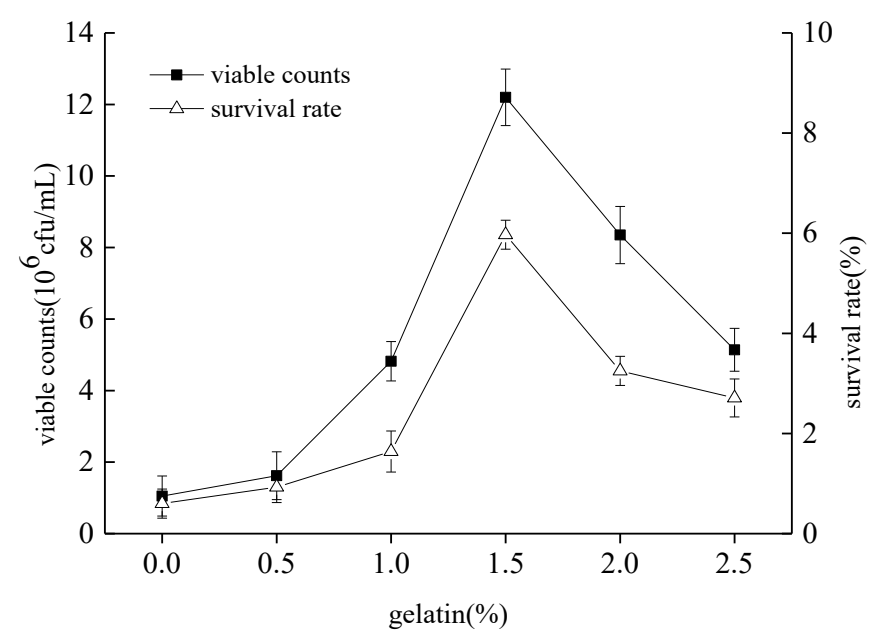

Figure 5. Effect of gelatin on the viable counts and survival rate of L.casei L61

\section{Effect of glycerol on viable counts and survival rate of L.casei $\mathrm{L61}$}

Adding sterilized and cooled glycerol solution to fermented goat milk by Lactobacillus casei L61 to make it add $0,4,6,8,10$ and $12 \mathrm{~mL} / \mathrm{L}$ $(\mathrm{v} / \mathrm{v})$ respectively. After heat treatment, the viable counts and the survival rate of the bacteria were calculated. The results were shown in Figure 7.

According to the Figure 7, within the range of glycerol addition, with the increase of glycerol addition, the number of viable bacteria and the survival rate reached the maximum at $8 \mathrm{~mL} / \mathrm{L}$ of glycerol, which were $2.75 \times 10^{6} \mathrm{CFU} / \mathrm{mL}$ and $4.71 \%$ respectively. With the continuous increase of glycerol content, the number of viable bacteria and the survival rate of bacteria in fermented milk decreased sharply. The results showed that the heat resistance of Lactobacillus casei L61 could be significantly enhanced by adding a certain amount of glycerol to fermented goat milk $(p<0.01)$.

Pan et al. (2005) studied that when glycerol content increased from $1 \%$ to $5 \%$, the survival rate of bacteria showed a gradual upward trend, which was consistent with the trend of this experiment.

\section{Effect of trehalose on viable counts and survival rate of L.casei $\mathrm{L61}$}

The trehalose solution after sterilization and cooling was added to the fermented milk of Lactobacillus casei L61, and the amount of trehalose added was $0,5,10,15,20$ and $25 \%$

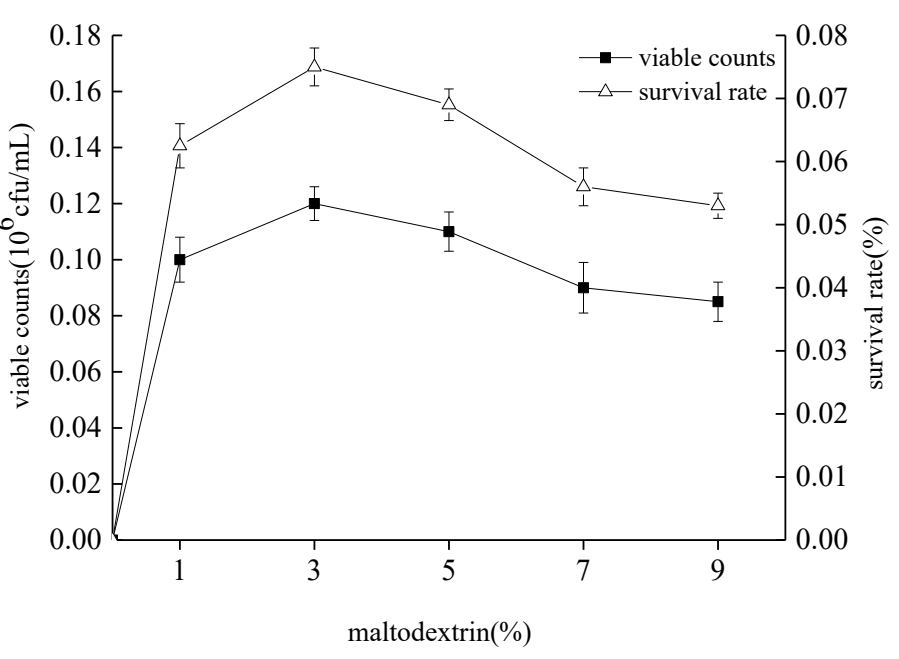

Figure 6. Effect of maltodextrin on viable counts and survival rate of L.casei L61

(w/v), respectively. The colonies were counted after heat treatment and the survival rate of the bacteria was calculated. The results were shown in Figure 8.

A certain amount of trehalose was added to fermented goat milk as heat-resistant protector of Lactobacillus casei L61. As can be seen from the Figure 8, the number of viable bacteria and viability of fermented milk increased rapidly in unit volume. With the increase of trehalose content, the number of viable bacteria and viability increased first and then decreased $(p<0.05)$. When the dosage increased to $10 \%$, the number of viable bacteria and the survival rate of bacteria reached the maximum, $0.435 \times 10^{6} \mathrm{CFU} / \mathrm{mL}$ and $0.29 \%$, respectively. With the increase of the dosage, the number of viable bacteria and the survival rate began to decrease.

The results of this study were consistent with those of Lactobacillus acidophilus and Bifidobacterium (Fan et al., 2011).

Studies have shown that the protective mechanisms of most protective agents can be roughly divided into three types: one is to enhance the tolerance of probiotic cells to adverse environments, the other is to provide some physical shield to protect the cells, and the third is that the protective agents have good drying kinetics (Agudelo et al., 2017; Su et al., 2018). Anekella,et,(2013) proved that maltodextrin ensured the high survival rate of probiotics in spray drying.

De Giulio et al. (2005): Some low molecular 
weight sugars (maltose, glucose, trehalose and sucrose) were proved that these sugars as protectants enhanced the survival rate of LAB. These sugars can protect microorganisms by acting on the polar groups of phospholipids in cell membranes through hydrogen bonds ( $\mathrm{Su}$ et al., 2018). Jae-young et al. (2014) study showed that the survival rate of Lactobacillus casei reached the highest when 1\% sucrose solution was added in the process of SFD (Her et al., 2015 ). Microencapsulation with trehalose has the best protective effect on

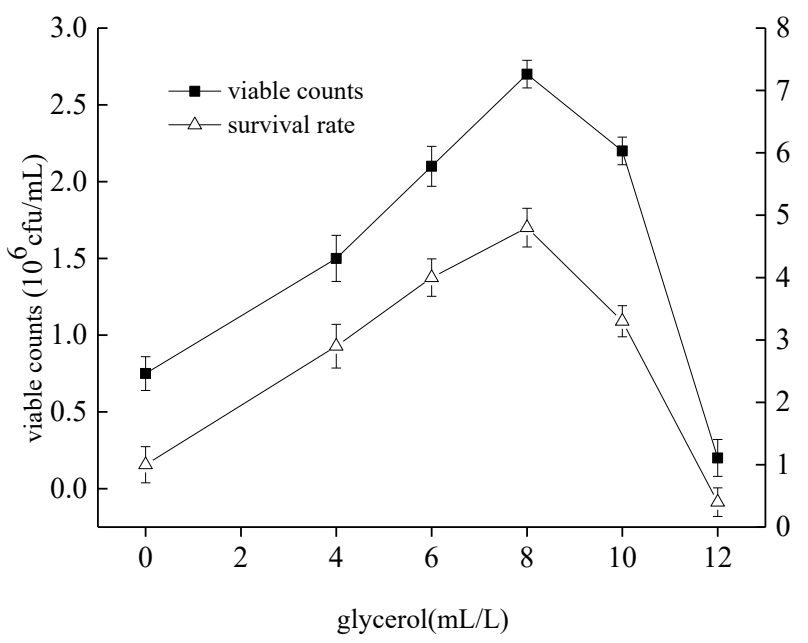

Figure 7. Effect of glicerol on the viable counts and survival rate of L.casei L61

\section{CONCLUSION}

In this study, the effects of thermal protectants on the spray drying of goat milk fermented by Lactobacillus casei L61 had been verified. The survival rate of Lactobacillus casei was enhanced in varying extent by adding appropriate concentration of heat-resistant protectant in fermented goat milk. Among all the thermal protectants, skim milk, sucrose, glucose, gelatin, glycerol, trehalose exhibited significant promotion on the survival rate of Lactobacillus casei in heat treatment $(p<0.05)$.
Lactobacillus acidophilus (Nunes et al., 2017; $\mathrm{Su}$ et al., 2018). Gelatin is a denatured protein, which is easy to agglutinate when dissolved in water and has good water holding capacity. It can improve the heat resistance of bacteria by preventing cell deformation (Sultan et al.2015). Skim milk has a good thermal protective effect. The reason may be that whey protein can form a layer of protein membrane outside the cell wall of bacteria, which can reduce the damage of cell wall and cause the exudation of intracellular substances.

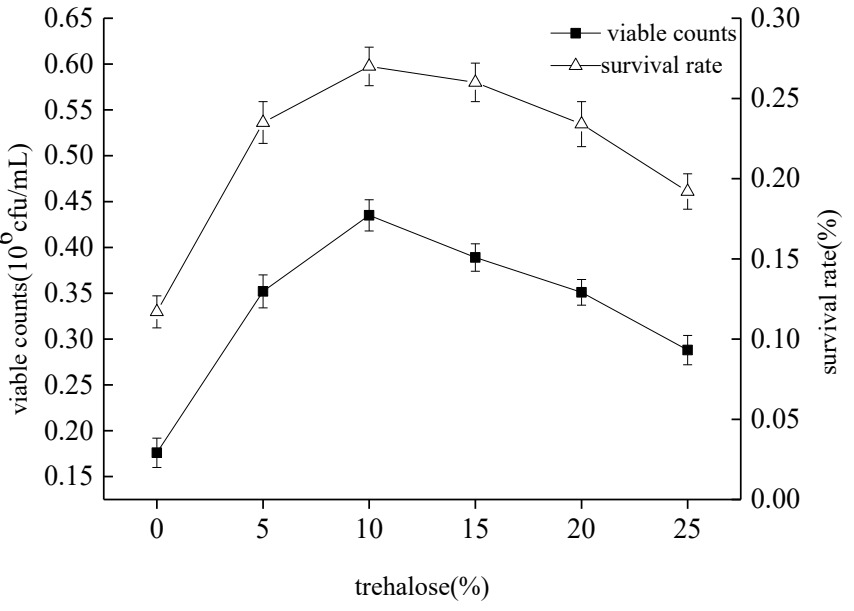

Figure 8. Effect of trehalose on viable counts and survival rate of L.casei L61

The optimal of skim milk, sucrose, glucose, gelatin, glycerol, trehalose to goat milk was $20 \mathrm{mg} / \mathrm{L}, \quad 10 \%, \quad 7 \%, \quad 1.5 \%, 8 \mathrm{~mL} / \mathrm{L}, \quad 10 \%$, respectively. To the extent, the use of such heat-resistant protectants in spray drying offers a potential tool to increase the survival rate of Lactobacillus casei. The results of this experiment provide a reference for the development of composite heat-resistant protectant, and provide technical support for the development of antioxidant peptide probiotic goat milk powder.

\section{ACKNOWLEDGEMENT}

The work was partially supported by the key project of Science and Technology Department of Shaanxi Province (No. 2018ZDXM-NY-085), the science and technology project of Xi'an city [201806118YF06NC14(2)] and the Key Research and Development Program of Shaanxi (Program No. 2019ZDLNY06-01). 


\section{REFERENCES}

1. Anekella, K., \& Orsat, V. (2013). Optimization of microencapsulation of probiotics in raspberry juice by spray drying. LWT - Food science and Technology,50.17-24. http://dx.doi.org/10.1016/j.lwt.2012.08.003

2. Agudelo, J., Cano, A., González-Martínez, C., \& Chiralt, A. (2017). Disaccharide incorporation to improve survival during storage of spray dried, lactobacillus rhamnosus, in whey protein-maltodextrin carriers. Journal of Functional Foods, 37, 416-423.

3. Ananta, E., Volkert, M., \& Knorr, D. (2005). Cellular injuries and storage stability of spray-dried lactobacillus rhamnosus GG. International Dairy Journal, 15(4), 399-409.

4. Chávez, B. E. \& Ledeboer, A. M. (2007). Drying of probiotics: optimization of formulation and process to enhance storage survival. Drying Technology, 25(7-8), 1193-1201.

5. Chen, H., et al. (2017). Effects of six substances on the growth and freeze-drying of Lactobacillus delbrueckii subsp. bulgaricus. Acta Scientiarum Polonorum Technologia Alimentaria, 16(4): 403-412.

6. Chen, H., Ji, Z., Shu, G. W., \& Xing, H. N. (2012). Effect of probiotic lactobacillus strains on angiotensin i converting enzyme inhibitory activity from fermented goat milk. Advanced Materials Research, 531, 442-445.

7. Fan, N., Chen, X. F. et al. (2011). Study of Thermal Resistant Protective Agents of Probiotics. Food Research And Development, 32(4):94-96.

8. Gharsallaoui, A., et al. (2007). Applications of spray-drying in microencapsulation of food ingredients: An overview. Food Research International, 40(9): 1107-1121.

9. Giulio, B. D., Orlando, P., Barba, G. et al. (2005). Use of alginate and cryo-protective sugars to improve the viability of lactic acid bacteria after freezing and freeze-drying. World Journal of Microbiology \& Biotechnology, 21(5):739-746.

10. Haenlein, G. F. W. (2004). Goat milk in human nutrition. Small Ruminant Research, 51(2):155-163. 10.1016/j.smallrumres.2003.08.010

11. Her, J. Y., Min, S. K., \& Lee, K. G. (2015). Preparation of probiotic powder by the spray freeze-drying method. Journal of Food Engineering, 150, 70-74.

12. Isolauri, E., Juntunen, M., Rautanen, T., Sillanaukee, P., Koivula, T. et al. (1991). A human Lactobacillus strain (Lactobacillus casei sp strain GG) promotes recovery from acute diarrhea in children. Pediatrics, 88(1):90-7.

13. Johansen, E. (2018). Use of Natural Selection and Evolution to Develop New Starter Cultures for Fermented Foods. Annu Rev Food Sci Technol, 9: 411-428.

14. Mandal, S., Puniya, A. K., \& Singh, K. (2006). Effect of alginate concentrations on survival of microencapsulated lactobacillus casei ncdc-298. International Dairy Journal, 16(10), 1190-1195.

15. Nunes, G. L., Etchepare, Mariana de Araújo, Cichoski, Alexandre José, Zepka, L. Q., Jacob Lopes, E., \& Barin, J. S., et al. (2017). Inulin, hi-maize, and trehalose as thermal protectants for increasing viability of lactobacillus acidophilus encapsulated by spray drying. LWT - Food Science and Technology, 89(2018)128-133.

16. Pan, X. L., et al. (2005). Study on Protective Reagent of Lactobacillus Milk Powder. J. of Heilongjiang August First Land Reclamation University, 17(2):79-82.

17. Posecion, N. C., Crowe, N. L., Robinson, A. R. et al. (2005). The development of a goat's milk yogurt. Journal of the Science of Food and Agriculture, 2005, 85(11):1909-1913. $10.1002 /$ jsfa.2190.

18. Shu, G., Wang, S., Chen, He., Hu, M., Qin, T., \& Ma, Qi. (2015). The Effect of Feeding Neutralizer on the Growth of Bifidobacterium Bifidum, Acta Universitatis Cibiniensis. Series E: Food Technology, 19(1), 11-18.

19. Shu, G., et al. (2018). Antioxidant peptides from goat milk fermented by lactobacillus casei L61: preparation, optimization, and stability evaluation in simulated gastrointestinal fluid. Nutrients, 10(6), 797-810.

20. Su, Y., Zheng, X., Zhao, Q., Fu, N., Xiong, H., \& Wu, W. D. et al. (2018). Spray drying of Lactobacillus rhamnosus GG with calcium-containing protectant for enhanced viability. Powder Technology, https://doi.org/10.1016/j.powtec.2018.09.082. 
21. Sultan, A., Mustafa, E., Ismail, T., Ayhan, T. et al. (2015). Microencapsulation of probiotic saccharomyces cerevisiae var. boulardii with different wall materials by spray drying. $L W T$ Food Science and Technology, 63(1), 685-690.

22. Sunny-Roberts, E. O., \& Knorr, D. (2009). The protective effect of monosodium glutamate on survival of lactobacillus rhamnosus gg and lactobacillus rhamnosus e-97800 (e800) strains during spray-drying and storage in trehalose-containing powders. International Dairy Journal, 19(4), 209-214.

23. Ying, D., et al. (2012). Enhanced survival of spray-dried microencapsulated Lactobacillus rhamnosus GG in the presence of glucose. Journal of Food Engineering, 109(3): 597-602.

24. Yonekura, L., et al. (2014). Microencapsulation of Lactobacillus acidophilus NCIMB 701748 in matrices containing soluble fibre by spray drying: Technological characterization, storage stability and survival after in vitro digestion. Funct Foods, 6(100): 205-214. 